\title{
ACTIVE LeARNing in a SECOND YeAR SuRVeying CoURSE
}

\author{
Elena Rangelova and Sheng Lun Cao \\ Department of Geomatics Engineering, Schulich School of Engineering, University of Calgary \\ evrangel@ucalgary.ca
}

\begin{abstract}
As a course that develops both cognitive and psychomotor skills of geomatics engineering students, the second-year surveying course at the University of Calgary has been re-designed to include more active, constructive and interactive learning experiences. Classroom activities have been designed around the idea that a balance between the four levels of learning in the ICAP (interactive-constructive-active-passive) framework should be achieved. Passive learning is acceptable because it provides students with time to accumulate knowledge and overcome their initial uncertainty in the surveying classroom. Eventually, their learning undergoes transformation most notably during the interactive team-based field labs.

An observation protocol has been designed, which, in addition to mapping student learning, assesses the teaching and learning environment and specifically its student cognitive and behavioural engagement aspects. The provisional results in winter 2019 confirmed that the geomatics engineering students were more engaged in the learning process as the time spent practicing active and constructive learning accounted for $78 \%$ of the class time in three observed lectures.
\end{abstract}

Keywords: active learning, passive learning, the ICAP framework, cognitive engagement, geomatics engineering

\section{INTRODUCTION}

Geomatics engineering is a multifaceted engineering discipline, which is deeply rooted in surveying. The second-year surveying course in the Department of Geomatics Engineering at the University of Calgary equips students with a set of technical skills and fundamental knowledge required in a few third and fourth-year courses.

Teaching and learning in this course have followed a very traditional approach for many years. Students would listen to a lecture and copy equations and diagrams in skeleton lecture notes. Then, the students would receive a lab handout, complete the required field work and write a group lab report. Although the students seemed to engage in the learning process, their cognitive engagement in class remained relatively low due to the limited number of open-ended questions, discussions and problem solving.
In the past few years, the use of lecture slides with examples worked out in class did not significantly improve the student cognitive engagement.

In winter 2018, a study was conducted to tackle this problem. The research methodology explained in detail in [1] used classroom observations covering four categories of the teaching and learning environment: (1) geomatics content, (2) instruction and feedback, (3) student cognitive engagement, and (4) student behavioural engagement. Figure 1 shows the scores for these four categories computed as weighted averages of the scores of five or six criteria defined in each category [1]. The variation of the length of the bar shows an improvement, or a lack thereof, of the teaching and learning environment in the surveying classroom. The behavioural engagement was high (a score of 2.8 out of 3 ) when students took notes and unsatisfactory (1.8 out of 3 ) to good (2.3 out of 3 ) when teaching used slides and less writing on the board. On average, the course scored low (67\%) in the cognitive engagement category due to the limited number of open-ended questions and discussions.

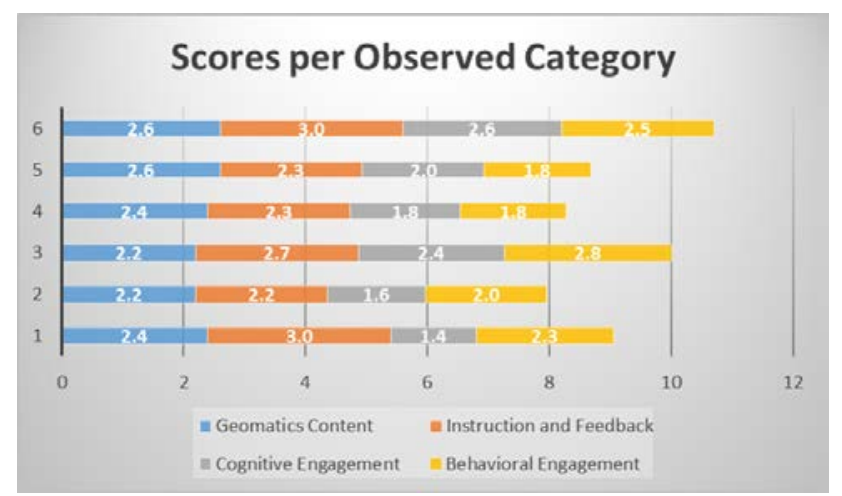

Fig. 1: Scores for six observed lectures in the 2018 second year surveying course. The scale is 0 (not observed), 1 (minimal), 2 (to some extent), and 3 (emphasized).

Evidently, a thorough examination and revision of the teaching and learning methods in this course has been overdue. One way to possibly improve student learning is to flip the course [2]. The flipped surveying classroom typically uses videos $[3,4]$ to demonstrate routine field 
and computation procedures in pre-class activities. This approach has been successful [4] because knowledge in surveying is mostly procedural, i.e., students learn by iterating field and office work. While a video is an invaluable tool to demonstrate surveying skills, it should be customized in order to fit the learning outcomes of the specific surveying course.

A different approach is adopted in this work. It is situated in the Interactive-Constructive-Active-Passive (ICAP) framework [5,6]. To the authors' knowledge this may be the first attempt to use this taxonomy of learning in geomatics engineering. Its novel use here stems from the idea of the necessary contextualization of active learning in engineering [7]. In addition, a new hybrid observation protocol is designed to assess the teaching and learning environment together with active learning.

\section{THEORETICAL FRAMEWORK}

According to ICAP [6], learning is characterized as:

1. Passive: students store information, which remains inert until it is triggered for a specific learning goal. Passive learning is void of active engagement with the course material. Students may pay attention to the lecture but make no effort to participate, for example, by taking notes.

2. Active: students integrate new information by making connections to prior knowledge, which is activated in order to accomplish a specific learning goal. If the students take notes, their learning is active.

3. Constructive: students infer new knowledge from the integrated knowledge in (2) by (a) reflecting on it, (b) reconsidering and reevaluating the connections between the existing and new knowledge structures, (c) contrasting ideas and solutions, (d) inducing information, etc. Participating in a class discussion is categorized as constructive learning.

4. Interactive: knowledge is "co-inferred" when students collaborate on a learning task. In doing so a student may store information, activate and reevaluate prior knowledge. Thus, the interactive learning is the most complex mode of learning as the student transitions through the different modes with the help of their peer(s). This process is illustrated in Figure 2. In surveying, interactive learning usually occurs naturally when students explain to each other the steps of an observation or computation procedure.

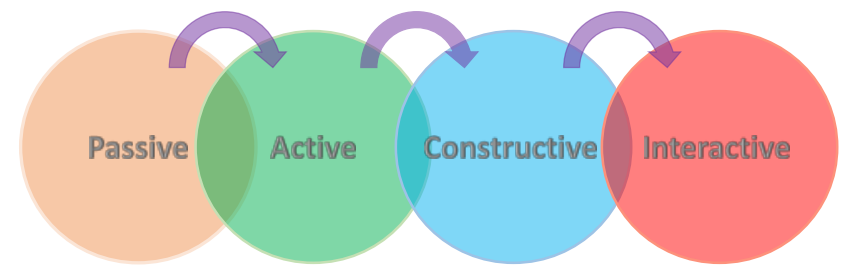

Fig. 2: Levels of learning according to the ICAP theory.

\section{DESIGNING LEARNING ACTIVITIES}

Class activities are re-designed and new activities planned in the following procedure:

1. Divide each course unit/chapter in portions, i.e. lessons. A lesson can be defined as a series of interconnected teaching and learning activities addressing one concept or few simple concepts combined such that students can exploit various aspects of one complex concept. Ideally, a lesson would fit in a fifty-minute academic lecture, but some lectures may include two shorter lessons.

2. For each lesson define measurable learning goals. Use verbs such as compute, explain, measure, demonstrate, analyze and discuss, to name a few (see Figure 3). The learning goals should be accomplished during the lesson. Therefore, they must address either simple concepts or single aspects of complex concepts. Some surveying examples of learning goals corresponding to different levels of cognitive engagement [8] are:

- Knowledge retrieval: be able to correct a measured distance for systematic errors.

- Comprehension: be able to explain in which ways systematic errors affect a measured distance.

- Analysis: be able to categorize the environmental effects on a measured distance with respect to gross, random and systematic errors.

As shown in Figure 3, the lessons' learning goals are the constituents of the chapter learning outcomes, which themselves contribute to the general course outcomes and engineering graduate attributes.

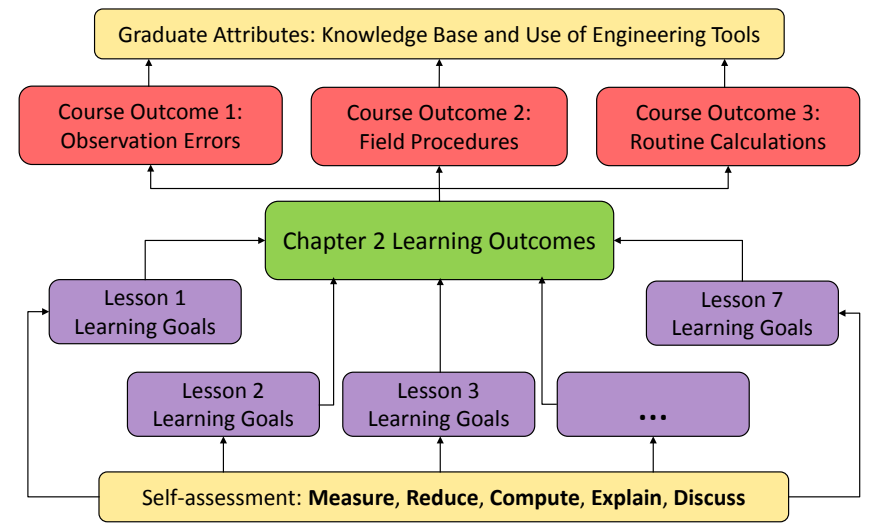

Fig. 3: The hierarchy of the learning outcomes in the second-year surveying course.

3. In each lesson, plan at least one learning exercise with a specific cognitive goal. Student can

- perform a simple calculation and share the answer with the class;

- solve a problem on the board with students participating and commenting on the outcome; 
- review the course notes and note down questions to be submitted to the teacher;

- participate in demonstrations of survey equipment in class;

- $\quad$ work in pairs and explain a concept to each other;

- search for, extract and apply relevant information in manuals and technical documentation;

- connect new information to old knowledge;

- discuss real-world applications of learned concepts;

- debrief labs and share hands-on experiences with the rest of the class; and

- compile a list of questions to address in a lab report.

This list does not exhaust all possible class activities, but it is important for a course like surveying with a lot of hands-on experience and procedural learning to cover both the cognitive and psychomotor learning domains. The latter activities are usually positioned in the middle of the lesson to illustrate the use of a surveying instrument or an observation procedure and revitalize the students' attention after spending the first thirty minutes of the lesson on learning the required conceptual knowledge.

4. Plan constructive and interactive exercises towards the end of the course unit. These more advanced forms of learning can happen when students feel confident in their conceptual knowledge. The instructor should acknowledge the uncertainly of the students by engaging them in a discussion as a form of interactive learning to clarify the not-so-obvious aspects of the required theoretical knowledge. The increased confidence in their understanding and skills makes the students more willing to share knowledge and ideas with their peers.

Naturally, most constructive and interactive learning in surveying happens before and during lab sessions with students working in teams of four to complete a field exercise and write a group lab report. The constructive learning is focused mainly on designing and refining the field observation procedures, while interactive learning happens when a team member with a specific role and related responsibilities in the lab exercise explains a procedure to the rest of the team. Some of these scenarios can be used in lectures. An example of constructive learning is outlining the skeleton of a lab procedure individually as well as with the active participation of the entire class. Students also engage in interactive learning when they share their experiences in mitigating problems encountered in the field work.

5. Iterate the procedure to find a reasonable balance between the four levels of learning. It is unrealistic to expect that all students will remain engaged in active learning in all fifty minutes of a standard academic lecture. Students, who very actively engage in the learning process may be bored when the teacher reiterates information to bring the entire class up to the required speed and place. In other words, passive learning may occur often despite the best intentions of the teacher to design an optimal learning experience for all students.

In the authors' opinion, passive learning is acceptable provided that a balance is achieved between the four levels of learning in each lesson and the course unit/chapter. Table 1 shows the time distribution of the activities addressing the four levels of learning in two lessons \#6 and \#7 (see Appendix A) of one lecture. This budget is also shown for the entire chapter, which consists of approximately four fifty-minute lectures. Active, constructive and interactive learning together account for $71 \%$ of the duration of the chapter. In $29 \%$ of the chapter's duration, the teaching method can trigger passive learning.

Perhaps it is interesting to explore few examples of passive learning. Arguably students looking at lecture slides and listening to the teacher can be categorized as passive learning [6]. Passive learning can also occur when students perform activities not related to the course but still paying attention to the lesson. A student can quietly observe a demonstration and not taking notes or engaging in a subsequent discussion. It is difficult to differentiate between students being passive, i.e., not engaging in the learning process, and engaged but covertly storing information. This ambiguity is pictured by the larger overlap between the passive and active learning in Figure 2. Therefore, the teacher should obtain evidence (snapshots) of the cognitive engagement at a few instances during the lesson. A spontaneously asked question gauges student learning. Students can be asked impromptu to recall information, make a connection to a similar case, or differentiate between cases, outcomes, effects, etc. They can draw from their hands-on experience to evaluate a procedure explained by the teacher. It is very common in surveying to have students with industry experience. The teacher can ask those students to provide examples of real-world applications.

Table 1: Time count in minutes for each mode of learning per lesson, lecture (see Appendix A) and chapter.

\begin{tabular}{|l|c|c|c|c|c|}
\hline \multirow{2}{*}{$\begin{array}{l}\text { Learning } \\
\text { level/mode }\end{array}$} & \multicolumn{2}{|c|}{ Lesson } & Lecture & \multicolumn{2}{c|}{ Chapter } \\
\cline { 2 - 6 } & $\# 6$ & $\# 7$ & $\# 6$ and \#7 & \multicolumn{2}{|c|}{ Total } \\
\cline { 2 - 6 } & $\min$ & $\min$ & $\min$ & $\min$ & $\%$ \\
\hline Passive & 10 & 5 & 15 & 61 & 29 \\
\hline Active & 11 & 9 & 20 & 108 & 51 \\
\hline Constructive & 2 & 8 & 10 & 29 & 13 \\
\hline Interactive & 5 & 4 & 9 & 14 & 7 \\
\hline Total & 28 & 26 & 54 & 212 & 100 \\
\hline
\end{tabular}




\section{ASSESSMENT OF STUDENT LEARNING}

A short self-assessment form is included at the end of each lesson so that students can assess the level of confidence in their knowledge related to the taught concepts. The students can rank their confidence using seven categories in a Likert scale starting with the "total lack of confidence" and ending with "very confident". The teacher can also ask the students to reflect and rank the covered concepts in terms of their difficulty. This is yet another example of constructive learning.

\subsection{Classroom Observation Protocol}

Classroom observations can be conducted in order to provide an objective assessment of the impact of the teaching approach discussed herein. The goal is to collect a fine grain data of the class response to the teaching interventions. One such protocol based on the ICAP framework is ELCOT [9, 10].

The observation protocol designed in this study is context-specific [7] and hybrid. It can be used to evaluate the teaching and learning classroom environment. Similar to ELCOT, detailed mapping (with a frequency of 2 minutes) of the teacher-student interactions in class is suggested. Table 2 shows the set of observation codes characterizing the teacher behaviour, and Table 3 shows the codes for the student behaviour grouped in the four levels of learning.

Table 2: Codes for mapping the teacher behaviour.

\begin{tabular}{|l|l|}
\hline TEX & Explains a concept \\
\hline TAQ & Answers a question \\
\hline TPQ & Poses a question \\
\hline TWB & Writes on the board \\
\hline TW & Waits for the class to finish an activity \\
\hline TMO & $\begin{array}{l}\text { Moves through the class and observes students } \\
\text { doing an activity }\end{array}$ \\
\hline TDG & Discusses with a group of students \\
\hline TDC & Discusses with the entire class \\
\hline TC & Draws a conclusion \\
\hline TGA & Assigns a group activity \\
\hline TF & Provides feedback to the class \\
\hline TAD & Performs administration work \\
\hline TI1S & Interacts with one student \\
\hline
\end{tabular}

\subsection{Assessment of the Teaching and Learning environment}

The second part of the classroom observation protocol includes the assessment of the teaching and learning environment according to [1]. The outcome of this assessment can be a chart similar to Figure 1, which will expose a trend of improvement in the teaching and learning environment, or a lack thereof. The assessment method has been updated to enhance its objectivity by utilizing the codes in Tables 2 and 3. Table 4 shows a summary of the students' behavioural engagement and the related codes. Similarly, Table 5 synthesizes the student cognitive engagement. A minor alteration is the change in the Likert scale (compare it with the one used in Figure 1) as follows: 0 (not observed), 1 (minimal), 2 (acceptable), 3 (emphasized), and 4 (strongly emphasized).

Table 3: Codes for mapping the student behaviour.

\begin{tabular}{|l|l|l|}
\hline SL & Listen to the teacher's explanation & \\
\hline SW & Wait for the teacher & \\
\hline STPE & $\begin{array}{l}\text { Talk to peers during the teacher's } \\
\text { explanation }\end{array}$ & \\
\hline SNP & Do not participate in activities & \\
\hline SNA & Occupied with unrelated activities & \\
\hline STN & Take notes & \\
\hline SPQT & Pose a question to the teacher & \\
\hline SPQP & Pose a question to peers & \\
\hline SWI & Work individually & \\
\hline SRN & Read their notes & \\
\hline SDG & Draw a graph & \\
\hline SSS & Suggest a solution & \\
\hline SDP & Design a procedure \\
\hline SPE & Provide evidence & \\
\hline SDO & Discuss outcomes & \\
\hline SCA & Choose an alternative \\
\hline SIP & Iterate a process/procedure & \\
\hline SR & Reflect on learning & \\
\hline SEC & Explain a concept & \\
\hline SES & Explain a solution & \multirow{2}{*}{} \\
\hline SEP & Explain a procedure & \\
\hline SPS & Provide a summary & \\
\hline SRF & Respond to feedback & \\
\hline SD & Debate & \\
\hline SP & Present & \\
\hline
\end{tabular}

Table 4: A summary of the student behavioural engagement.

\begin{tabular}{|c|l|l|}
\hline No & Criteria & Codes \\
\hline \multirow{2}{*}{1} & $\begin{array}{l}\text { Students followed directions, } \\
\text { responded to teacher's questions, } \\
\text { and were engaged in tasks during } \\
\text { the lesson. }\end{array}$ & $\begin{array}{l}\text { STN, SRN, } \\
\text { SWI, SDG, } \\
\text { SDO, SEC, } \\
\text { SES, SEP }\end{array}$ \\
\hline 2 & $\begin{array}{l}\text { Students asked the teacher or their } \\
\text { peers' questions }\end{array}$ & $\begin{array}{l}\text { SPQT, } \\
\text { SPQP }\end{array}$ \\
\hline 3 & Students reflected on their learning. & SR \\
\hline 4 & $\begin{array}{l}\text { Students requested and worked } \\
\text { with feedback. }\end{array}$ & SRF, SR \\
\hline 5 & $\begin{array}{l}\text { Students showed perseverance } \\
\text { when solving a problem. }\end{array}$ & $\begin{array}{l}\text { SPE, SDO, } \\
\text { SIP }\end{array}$ \\
\hline
\end{tabular}


Table 5: A summary of the student cognitive engagement.

\begin{tabular}{|c|l|l|}
\hline No & Criteria & Codes \\
\hline 1 & $\begin{array}{l}\text { Students discussed open ended } \\
\text { questions that required higher } \\
\text { level of thinking. }\end{array}$ & $\begin{array}{l}\text { SSS, SDP, } \\
\text { SDO }\end{array}$ \\
\hline 2 & Students justified their thinking. & $\begin{array}{l}\text { SPE, SIP, } \\
\text { SD, SP, SEC }\end{array}$ \\
\hline 3 & $\begin{array}{l}\text { Students summarized, synthesized } \\
\text { and generalized information. }\end{array}$ & SDG, SPS \\
\hline 4 & $\begin{array}{l}\text { Students contrasted alternative } \\
\text { solutions. }\end{array}$ & SCA \\
\hline 5 & $\begin{array}{l}\text { Students applied the acquired } \\
\text { knowledge in a novel situation. }\end{array}$ & $\begin{array}{l}\text { SSS, SD, } \\
\text { SP, SIP }\end{array}$ \\
\hline
\end{tabular}

\section{RESULTS}

In winter 2019, three sample surveying lectures were observed and the student and teacher behaviours coded according to Tables 3 and 4 . Figure 4 represents a summary of the observations of the student engagement in one of the lectures. Seven of the student behaviour modes in were observed, namely students (1) listening to the teacher's explanation (SL), (2) taking notes (TN), (3) posing a question to the teacher (SPQT), (4) suggesting a solution to a problem (SSS), (5) working individually (SWI), (6) being occupied with unrelated activities (SNA), and (7) talking to peers during the teacher's explanations (STPE). The vertical axis of the chart shows the number of the two-minute counts of each code. One can see that the students took notes during half of the lecture time (26 minutes) and spent about 18 minutes listening to the teacher. If the students listened and took notes, then one can conclude that they learned actively. However, if a portion of the class engaged in unrelated activities like checking their phones while still listening to the teacher, then the learning was classified as passive.

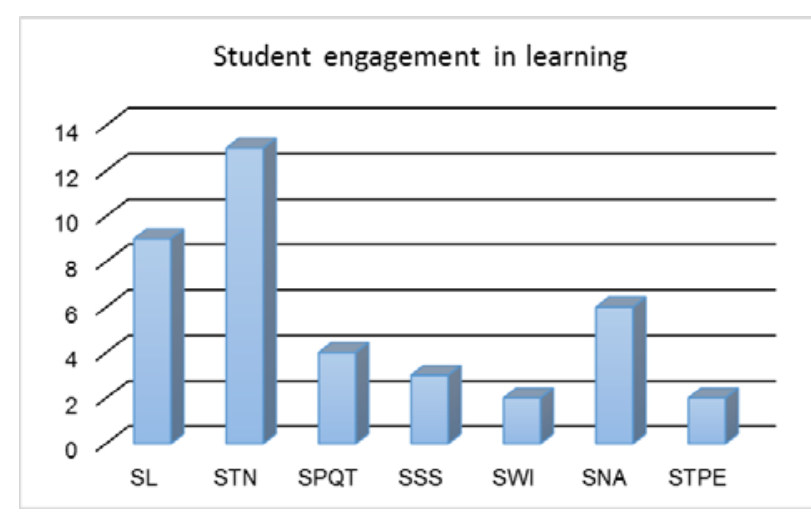

Fig. 4: Student engagement in an observed sample lecture. The vertical axis shows the number of twominute counts of each code.

Figure 5 supplements Figure 4 by showing the time spent on the modes of learning. The surveying students engaged in active and constructive learning in $81 \%$ of the lecture time. The active learning occurred mostly by means of taking notes, while the teacher wrote on the board examples as well as by students asking questions. The constructive learning occurred when the students suggested solutions to open-ended questions and by reflecting on their confidence in learned concepts.

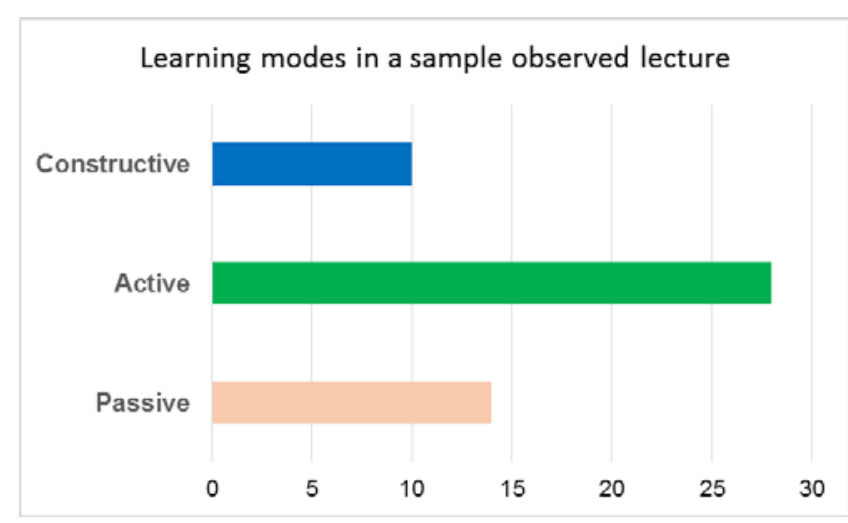

Fig. 5: Learning modes observed in the sample lecture against time in minutes.

\section{CONCLUSIONS}

This paper presented an ICAP-based approach to improve student learning in a second-year geomatics engineering course. The main goal was to enhance the student cognitive engagement by carefully structuring the lessons, defining simple and measurable learning goals, and designing a range of class activities that included singular and more complex tasks such as problem solving, student reflections on learning, constructing observation and calculation procedures, discussions of lab and project outcomes and demonstrations of survey observations in class. A balance between interactive, constructive, active and passive learning was aimed. The author argued that passive learning should be minimized but perhaps the teacher should not aim to eliminate it at any cost as it was difficult to distinguish between students who do not engage in the learning process and those who prefer to store information and increase their level of confidence before displaying more overt behaviour in class.

A classroom observation protocol was designed to map the student cognitive and behavioural engagement. The effectiveness of this new teaching approach in the secondyear course is currently evaluated, but the provisional observations and results confirm that the students have engaged more in the learning process compared to previous years as the time spent practicing active and constructive learning accounted on average for $78 \%$ of the three observed lectures. Despite being preliminary, our results show that the ICAP framework has been successfully implemented in its first iteration. The observation protocol is now being refined mostly in terms 
of better capturing the teaching and learning dynamics. More classroom observations will be done next year to draw statistically significant conclusions and assess the overall improvement of the teaching and learning environment in this course.

\section{Acknowledgements}

This work is supported financially by Schulich School of Engineering and Taylor Institute for Teaching and Learning, University of Calgary.

\section{References}

[1] Elena Rangelova, Ivan Detchev, and Scott Packer, "Quantifying deep learning in geomatics engineering by means of classroom observations" in Proc. Canadian Engineering Education Association (CEEA) Conf., (Vancouver, BC; 3-6 June 2018), 8 pp., 2019. Available as of December 12, 2018, from https://ojs.library.queensu.ca/index.php/PCEEA/article/vie w/13015

[2] Elena Rangelova and Jude Lacoste, "Challenges of flipping a course in geomatics engineering (8878)" in Proc. FIG Working Week 2017 Surveying the world of tomorrow - From digitalisation to augmented reality, (Helsinki, Finland, May 29-June 2, 2017), 8 pp., 2018. Available

from http://www.fig.net/resources/proceedings/fig_proceedings/ fig2017/papers/ts05g/TS05G_rangelova_lacoste_8878.pdf

[3] Negar M. Harandi, Farshid Agharebparast, Luis Linares, Samuel Dodson, Ido Roll, Matthew Fong, Dongwook Yoon, Sidney Fels, "Student video-usage in introductory engineering courses" in Proc. Canadian Engineering Education Association (CEEA) Conf., (Vancouver, BC; 36 June 2018), 8 pp., 2019. Available as of December 12, 2018,

from https://ojs.library.queensu.ca/index.php/PCEEA/article/vie w/13025

[4] Stephanie Koska and Louise Condra "More time for hands-on learning: Flipping the engineering classroom in a polytechnic" in Proc. Canadian Engineering Education Association (CEEA) Conf., (Vancouver, BC; 3-6 June
2018), 8 pp., 2019. Available as of December 12, 2018, from https://ojs.library.queensu.ca/index.php/PCEEA/article/vie $\mathrm{w} / 12973$

[5] Michele T.H. Chi, “Active-Constructive-Interactive: A Conceptual Framework for Differentiating Learning Activities”, Topics in Cognitive Science, 1(1), pp. 73-105. DOI:10.1111/j.17568765.2008.01005.x

[6] Michelene T.H. Chi and Ruth Wylie, "The ICAP framework: Linking cognitive engagement to active learning outcomes” Educational Psychologist, vol. 49:4, 2014, pp. 219-243, DOI: 10.1080/00461520.2014.965823

[7] R. A. Streveler, and M. Menekse, "Taking a closer look at active learning", Journal of Engineering Education, 106(2), 186-190.

[8] R. Marzano, and J. Kendall, The new taxonomy of educational objectives. Thousand Oaks, CA: Corwin Press. 2007.

[9] T. K. Tolnay, Sam Spiegel, Jennifer Z. Sherer, "Development of the engineering learning classroom observation tool (EL-COT)" in Proc. American Society for Engineering Education (ASEE) Annual Conference and Exposition (Columbus, OH; 25-28 June 2017), 19 pp., 2017. Available from https://www.asee.org/public/conferences/78/papers/18454/ view

[10] Megan Sanders, Sam Spiegel, Jennifer. Z. Sherer, "Moving beyond "Does active learning work" with the engineering learning observation protocol (ELCOT)", Proc. American Society for Engineering Education (ASEE) Annual Conference and Exposition (Salt Lake City, UT; 24-27 June 2018), 13 pp., Available from https://www.asee.org/public/conferences/106/papers/2343 $\underline{3 / v i e w}$

\section{APPENDIX A: PLANNING LESSON ACTIVITIES}

Table A1: Lesson activities

\begin{tabular}{|c|c|c|c|c|c|}
\hline $\begin{array}{c}\text { Lesson } \\
\#\end{array}$ & Slide \# & Teacher does & Students do & $\begin{array}{c}\text { Duration } \\
\text { in minutes }\end{array}$ & $\begin{array}{c}\text { Mode of } \\
\text { learning }\end{array}$ \\
\hline \multirow{6}{*}{6} & 2.50 & Explains equations & Solve an example & 4 & Active \\
\cline { 2 - 7 } & & Write a solution on the board & Write the solution & 2 & Active \\
\cline { 2 - 7 } & 2.51 & Explains a concept & Listen to the explanation & 4 & Passive \\
\cline { 2 - 7 } & 2.52 & Explains a concept & Listen to the explanation & 5 & Active \\
\cline { 2 - 7 } & 2.53 & Solves an example & Write the solution & & 2 \\
\hline
\end{tabular}




\begin{tabular}{|c|c|c|c|c|c|}
\hline & 2.54 & Explains a concept & Listen to the explanation & 4 & Passive \\
\hline & 2.55 & Observes students & Explain a concept to a peer & 5 & Interactive \\
\hline & 2.56 & Observes students & Reflect on learning & 2 & Constructive \\
\hline \multirow{11}{*}{7} & 2.58 & Explains concepts & Listen to the explanation & 3 & Passive \\
\hline & & Solve an example on the board & Write the solution & 2 & Active \\
\hline & 2.59 & Observes students & Explain each other a concept & 2 & Interactive \\
\hline & & Observes students & Solve examples in pairs & 2 & Interactive \\
\hline & & Writes answers on the board & Compare their answers & 2 & Active \\
\hline & 2.60 & Reads a problem and asks questions & Construct a solution & 3 & Constructive \\
\hline & & Observes students & Solve the problem & 2 & Active \\
\hline & & Writes the solution & Compare their solution & 3 & Active \\
\hline & 2.61 & Explains a concept & Listen to the explanation & 2 & Passive \\
\hline & & $\begin{array}{l}\text { Writes the students' solution on the } \\
\text { board }\end{array}$ & Construct a solution & 3 & Constructive \\
\hline & 2.62 & Observes students & Reflect on learning & 2 & Constructive \\
\hline
\end{tabular}

